INVESTIGACIÓN/RESEARCH

\title{
EL LENGUAJE COMO REFERENTE DE LA TRASLACIÓN DEL DISCURSO ORAL AL ENTORNO DIGITAL: UN ESPACIO MULTIMEDIA E INTERACTIVO
}

Carlos Oliva Marañón1: Universidad Rey Juan Carlos (Madrid). España. carlos.oliva.maranon@urjc.es

\section{RESUMEN}

La vitalidad léxica de la Lengua Española es un hecho constatado. Un síntoma evidente de ello es la aparición de palabras nuevas en los medios de comunicación, algunas, mediante el cambio significativo de vocablos ya existentes; otras, tomadas de registros extranjeros, pero la mayoría formadas a partir de las propias reglas de la lengua. Ahora bien, la emergencia del nuevo entorno electrónico, con la presencia del habla fusionada en la escritura, ha logrado una nueva forma de lenguaje escrito, de libre flujo por la Red. De ese modo, la interacción mediante texto electrónico cobra una distancia significativa con respecto a las experiencias de escribir más tradicionales, ya que reactualiza una dinámica de comunicación semejante a las prácticas de la tradición oral de la conversación. Se ha analizado el léxico de algunos de los mensajes escritos a través de las Páginas Web de la serie de televisión El Barco, que ha acumulado altos índices de audiencia. Con su nueva aplicación interactiva, llamada Los Twittersodios, los espectadores pueden comunicarse con sus personajes a través de la Red Social Twitter. Mediante estos mensajes de texto puede apreciarse cómo el lenguaje ha sufrido una considerable transformación entre los usuarios de las Nuevas Tecnologías.

PALABRAS CLAVE: Lengua Española - Entorno digital - Competencia escrita - Series de Televisión - Redes Sociales

\footnotetext{
${ }^{1}$ Autor correspondiente:

Carlos Oliva Marañón: Profesor Doctor de la Facultad de Ciencias de la Comunicación. Universidad Rey Juan Carlos. Fuenlabrada (Madrid). España.

Correo: carlos.oliva.maranon@urjc.es
} 


\title{
THE LANGUAGE AS A REFERENCE FOR ORAL TRANSLATION OF SPEECH TO THE DIGITAL ENVIRONMENT: A MULTIMEDIA AND INTERACTIVE SPACE
}

\begin{abstract}
The lexical vitality of the Spanish Language is a fact. An obvious symptom is the appearance of new words in the media, some by the significant change in existing words, sometimes taken from foreign records, but most formed from the very rules of the language. However, the emergence of new electronic environment, with the presence of speech merged in writing has achieved a new form of written language, free-flowing by the Network. Thus, the interaction through electronic text becomes a significant distance regarding the experiences of more traditional writing as a dynamic communication reenacts similar to the practices of the oral tradition of the conversation. We analyzed the lexicon of some of the messages written through the Websites of the television series "The Ship", which has accumulated high ratings. With its new interactive application called "The Twittersodios", viewers can communicate with their characters through the social network Twitter. Through these texts can be seen how the language has shifted dramatically between users of New Technologies.
\end{abstract}

KEY WORDS: Spanish language - Digital environment - Written competence Television series - Social Networks

\section{INTRODUCCIÓN}

El origen del lenguaje ha cautivado desde tiempos remotos a la humanidad. La más antigua investigación sobre esta materia de la que tenemos referencia es la que nos cuenta el historiador griego Herodoto (484-420 a. de C.) acerca de un experimento realizado por el rey egipcio Psamético I, que vivió en el siglo VII antes de Cristo.

La adquisición del lenguaje ha preocupado a todas las culturas; en casi todas ellas pueden encontrarse relatos que lo asocian a un don divino. Para los japoneses, la diosa del sol, Amaterasu, fue la creadora del lenguaje. En China, fue el Hijo del Cielo, T'ientzu, quien dio el lenguaje a los hombres. Entre los griegos, su origen está asociado a Prometeo, quien al robar el fuego del Olimpo y traerlo a los hombres, hace que se tornen sociables y comiencen a hablar.

También, desde la antigua Grecia, Aristóteles se ocupaba del lenguaje de la comunicación a través de su Tratado sobre Retórica, definiéndola como la "búsqueda de todos los medios de persuasión que tenemos a nuestro alcance"2 (Berlo, 1969, p. 7). Los griegos, y posteriormente los romanos, desarrollaron el arte de la oratoria con el fin de aprender a hablar en público, siendo la persuasión su principal propósito y uno de los

2 Berlo, K. D. (1969). El proceso de la comunicación: Introducción a la teoría y la práctica. Buenos Aires: El Ateneo, p. 7. 
elementos que en la actualidad es utilizado por distintos estudiosos, para quienes no existe la comunicación a menos que el receptor del mensaje sea afectado.

Ya a finales del siglo $X X$, el lenguaje está muy condicionado por las Nuevas Tecnologías de la Información y de la Comunicación (NTIC). Entre estos avances es destacable la incursión de Internet, lo que ha propiciado el surgimiento de una industria del entretenimiento con características propias. Este nuevo escenario está impulsando activamente la presencia creciente de contenidos audiovisuales en la Red. Actualmente, el medio está aprovechando las potencialidades derivadas de su capacidad intrínseca de difusión, precisamente, es en el ámbito del entretenimiento donde se están desarrollando nuevos productos audiovisuales que, desde la hibridación de géneros y formatos consolidados, buscan tímidamente ajustarse a las potencialidades propias del medio.

A los "inmigrantes digitales", como denomina Alejandro Piscitelli ${ }^{3}$ a los adultos que no nacieron y se criaron en un entorno mediado por las Tecnologías de la Información y de la Comunicación (TIC), se intenta desvelar si estas nuevas formas de escritura derivadas del uso del chat y los mensajes de texto por telefonía $\mathrm{u}$ otros medios digitales constituyen nuevas formas de identidad lingüístico-cultural producidas como contracultura e identidades lingüísticas, o, si por el contrario, el uso de las TIC produce nuevas "identidades lingüísticas" como efectos secundarios. Distintos investigadores intentan analizar si la emergencia de un nuevo lenguaje escrito producido por los jóvenes a raíz del uso y apropiación de las TIC, especialmente, de Internet, significa la decadencia del lenguaje y de la cultura de la imprenta para las jóvenes generaciones ${ }^{4}$ (Galera, J. y Calandrelli, R., 2009).

Así, se intuye un cambio significativo que puede producirse en el panorama audiovisual con la creación de contenidos concebidos y realizados teniendo en cuenta al máximo las especificidades del medio electrónico y, en concreto, la interactividad. Para ello, la aparición de la Web 2.0 está afianzando de forma mucho más acelerada la aplicación de nuevos modelos narrativos que forman contenidos audiovisuales de creación colectiva, lo que está generando a su vez una cultura de la llamada "creación colectiva" o "inteligencia colectiva" que ofrece nuevas formas de expresión y comunicación en la Red ${ }^{5}$ (Lloret, N. y Canet, F., 2006).

Algunos autores han aportado definiciones del término comunicación desde muy diversas perspectivas:

- Gerbner la define como "la interacción social por medio de mensajes que pueden codificarse formalmente; son símbolos o sucesos que representan algún aspecto compartido de una cultura"6 (Blake, R. y Haroldsen, E., 1989, p. 3).

\footnotetext{
${ }_{3}^{3}$ Conferencia de Alejandro Piscitelli en el Centro Cultural San Martín el 16/08/05.

${ }^{4}$ Galera, J. y Calandrelli, R. Las Nuevas Tecnologías de Información y Comunicación y sus efectos en el lenguaje escrito en los adolescentes. http://www.adilq.com.ar/Resumen\%20Galera\%20Julieta-Calandrelli\%20Roc\%EDo.pdf

${ }^{5}$ Lloret, N. y Canet, F. (2006). "Nuevos escenarios, nuevas formas de expresión narrativa: la Web 2.0 y el lenguaje audiovisual", Hipertext.net, núm. 6.

${ }^{6}$ Blake, Reed, H. y Haroldsen, E. O. (1989). Una taxonomía de conceptos de la comunicación. México: Nuevomar, p. 3.
} 
- Berelson la caracteriza como "la transmisión de información, ideas, emociones o habilidades, mediante símbolos, palabras, imágenes, cifras, gráficos, etc."7 (Blake, R. y Haroldsen, E., 1989, p. 3).

De esta manera, en pocas ocasiones se llega al máximo nivel de participación del usuario, en el que emisor y el receptor intercambian sus posiciones. Habría que preguntarse si la interactividad conduce a mayores niveles de democracia ${ }^{8}$ (Sénecal, M., 1995, pp. 16-18). Esto sucede si los usuarios participan e interactúan en unos contextos tecnológicos en los que permanecen cautivos dentro de un universo comercial y comunicativo prefabricado y predeterminado. $\mathrm{O}$ si, por el contrario, la interactividad está al servicio de un proyecto de reapropiación crítica de los medios, basada en la reciprocidad y en altos grados de participación de los usuarios en procesos y productos comunicativos concebidos bajo modelos dialógicos (Cloutier, J., 1975 y Kaplún, M., 1998).

En definitiva, las Tecnologías de la Información y de la Comunicación y los usos derivados de ellas en los mensajes de texto han provocado un cambio sustantivo en el lenguaje escrito. Esta nueva forma de escritura se ha transformado en un fenómeno social que ha venido acompañada de no pocos debates apocalípticos o integrados ${ }^{9}$.

Por lo tanto, conviene analizar la calidad de estas nuevas formas de expresión (mensajes SMS, chats, blogs,...) que nos llegan a través de los medios digitales para, de esa forma, valorar en su justa medida nuestro patrimonio lingüístico. Por ejemplo, la acentuación, uso de mayúsculas y excesivo abuso de erratas, lo cual hace que encontremos textos muy poco dignos de definirse como escritos en la hermosa lengua de Cervantes.

\subsection{La sociedad y los medios de comunicación}

Los nuevos medios informáticos están modificando los modelos tradicionales de comunicación y de realización social. Vivimos, según los expertos, en una "Sociedad de la Información" y, sin embargo, la expresión "estar informado", cuyo valor epistémico la convertía en condición necesaria para saber más, ha pasado a designar una actitud más próxima a los límites borrosos de la semiótica de la imagen que a los de la lingüística de la palabra. La información se ha transformado en nuestros tiempos en un objeto de valor que hay que consumir compulsivamente. "Estar informado", en definitiva, significa ahora estar online en todo momento, es decir, "estar conectado"10 (Galán, C., 2009, pp. 81-82).

La industria del entretenimiento está empezando a vislumbrar que la Red no es solo un nuevo canal de distribución donde llevar sus reservas de contenido hacia otros

\footnotetext{
7 Ídem. p. 3.

8 Senecal, M. (1995). ¿La interconectividad conduce a la democracia? En: El Correo de la Unesco, vol. 48. París: Unesco, pp. 16-18.

9 Eco, U. (1999). Apocalípticos e Integrados. Barcelona: Lumen.

10 Galán, C. (2009). "El lenguaje del teléfono móvil" en SARMIENTO, R. y Vilches, F. La calidad del español en la Red. Nuevos usos de la lengua en los medios digitales. Barcelona: Ariel; Madrid: Fundación Telefónica, pp. 81-82.
} 
mercados; se sabe que la propia dinámica vitalista del medio no permite posturas conservadoras y que para ser competitiva deberá conocer qué es lo que el internauta demanda en un entorno online cuando accede a contenidos audiovisuales. La finalidad es poder diseñar productos a medida que sean capaces de causar un fuerte impacto entre la audiencia.

La evolución futura de Internet como medio de comunicación y entretenimiento pasa por el conocimiento y la fidelización de la audiencia actual y por el análisis de su comportamiento y necesidades. En este sentido, la industria del entretenimiento tendrá que crear y desarrollar en Internet productos destinados a los diversos segmentos de la población para mantener y asegurarse su fidelidad en el futuro. En consecuencia, los contenidos audiovisuales deberán desarrollar estrategias acordes con el perfil de las nuevas audiencias; por una parte, jóvenes entrenados en la interacción, formados en la cultura del ordenador, y, por otra, mayores que buscarán en la Red, además de información, entretenimiento, así como todo tipo de colectivos significativos o no que puedan interactuar en la Red.

A lo largo de la historia se han estudiado los medios de comunicación desde distintas perspectivas. ¿Cuáles son las razones por las que se estudian?

$>$ Por el alto grado de consumo, ya que dependemos de los medios.

$>$ Por su importancia ideológica, puesto que nos ofrecen el punto de vista desde el que se interpreta la realidad sociológica.

$>$ Por las normas y los valores sociales, ya que se construye por el contacto con los medios.

Como consecuencia de este estudio pormenorizado de los medios de comunicación, algunos autores han acuñado el término "sociedad de la imagen", cuyas características son las siguientes:

- Rapidez.

- Complejidad.

- Globalización de la información.

- Nuevas comunidades.

- Nuevos ámbitos de expresión.

- Intertextualidad.

- Cambios en la representación icónica.

- Transformaciones sociales y de consumo.

- Supresión de barreras espacio-temporales.

- Inéditas opciones para el entretenimiento y la información.

Por tanto, comunicar es el arte de relacionarse o contactar con los demás, lo que nos ayuda a tener una vida más fácil. Se trata de una habilidad que se aprende a medida que vamos creciendo. 
Pero, ¿de qué forma comunicamos?

Mediante la palabra (con o sin imagen).

$>$ A través de los gestos.

$>$ Al utilizar los medios audiovisuales.

De esta manera, al comunicar se emplean una serie de factores que van más allá del uso de la lengua porque hay que atraer la atención del espectador con entretenimiento. Por tanto, en la comunicación de masas, las expresiones o enunciados se manifiestan públicamente a través de medios técnicos de difusión a un público heterogéneo. Las diferencias con la comunicación interpersonal son las siguientes:

$>$ En la comunicación de masas, el emisor es colectivo, mientras que en la interpersonal es individual.

$>$ En la comunicación de masas se da el fenómeno de la audiencia, que es un grupo heterogéneo que vive en diferentes escalas culturales y que, en un determinado momento, coinciden en una misma realidad mediática.

> El canal es diferente en las dos comunicaciones.

$>$ Las probabilidades de persuasión son mayores en la comunicación de masas, ya que es un medio más rápido porque llega a todos.

$>$ El mensaje en la comunicación interpersonal "desaparece", mientras que en la comunicación de masas se convierte en producto de consumo.

\subsection{El lenguaje audiovisual}

La clave del lenguaje audiovisual es que el significado del mensaje viene dado por la interacción sonido-imagen dentro de un contexto secuencial. La música, los efectos sonoros, los ruidos y los silencios colaboran en la transmisión del mensaje no como fondo o complemento, sino conformando realmente el mensaje.

Técnicamente, el lenguaje audiovisual se compone de diversos aspectos, pero dicha composición no es solo la yuxtaposición de elementos visibles y audibles, sino su síntesis, creándose un nuevo elemento con sus propias características, posibilidades y limitaciones. A través de sonidos agudos o graves, imágenes comunes o impactantes y movimientos pausados o rápidos, el lenguaje audiovisual interpreta la realidad y ofrece una experiencia casi directa de ella.

\section{¿Cuáles son los elementos del lenguaje audiovisual?}

Morfológicos: formas que integran un discurso mediante diferentes elementos visuales y sonoros.

> Sintácticos: reglas con las que se unen u organizan las formas para construir el discurso. 
Dstéticos: propiedades de armonía, agrado y belleza en el discurso. Formas de color.

$>$ Los significados que se transmiten a través del discurso.

Además, cuando hablamos de lenguaje, nos referimos a un conjunto de signos. Según Umberto Eco, "un signo es un convenio de expresión", es decir, es una unión entre algo material (perceptible por los sentidos) y un concepto llamado significado. Un signo consta de tres propiedades:

$>$ Significado: es el concepto que en nuestra mente hace aparecer el significante.

$>$ Significante: es la representación del signo creada en nuestro cerebro.

$>$ Referente: es la realidad que el signo representa.

El estudio de los signos se presenta como una ciencia omnicomprensiva. Desde que se concibió la semiología o la semiótica en nuestro siglo, se ha postulado como una ciencia que incorpora toda la experiencia y todo el saber, ya que todo es signo, todo tiene esa doble faz de significante-significado (que puede también traducirse en términos de lo sensible y de lo inteligible): lo que sirve de signo suele llamarse "significante", mientras que a aquello a lo que se refiere el signo - aquello que da a conocer - se le llama "significado"11 (Eco, U., 1976, p. 11).

Umberto Eco llega a formular en su máxima radicalidad - si bien a modo de hipótesis - una interpretación estrictamente sígnica del mundo: "¿Y si el mundo entero y las cosas no fueran más que signos imperfectos de interpretantes ${ }^{12}$ externos, del mundo de las ideas? Toda la teoría platónica no es más que una doctrina del signo y de su referente metafísico (...). ¿Y si el mundo fuera el efecto de un designio divino que construye la naturaleza para poder hablar al hombre? (...). El universo es una teofanía: Dios, que manifiesta por signos qué son las cosas, y por medio de éstas nos encamina hacia la salvación"13 (Eco, U., 1976, pp. 110-111).

El autor discrepa de este modelo sígnico, ya que "para establecer una metafísica pansemiótica no es necesario que sobreviva el protagonista divino: basta con que predomine un sentido de la unidad del todo, del universo como cuerpo que se significa a sí mismo"14. Con todo, lo que resulta evidente, a partir de los estudios semióticos de Umberto Eco, es la necesidad de reflexionar filosóficamente sobre cuestiones que rebasan el ámbito lingüístico ${ }^{15}$. El problema del signo, del sentido y de la referencia no es meramente un problema de lenguaje, como lo ven destacados lingüistas actuales, sino que intervienen en la teoría de los signos la lógica, la gnoseología, la psicología, e incluso la metafísica.

\footnotetext{
11 Eco, U. (1976). Signo. Barcelona: Labor, p. 11.

$12 \mathrm{El}$ interpretante no es el sujeto que interpreta el signo, sino un signo con el que se interpreta otro signo. Vendría a ser una versión semiótica del sentido regano, en cuanto contenido conceptual evocado por el signo para manifestar lo significado. En Eco, sin embargo, lo significado no comparece jamás, pues no es posible salir del signo.

${ }^{13}$ Eco, U. (1976). Signo. Barcelona: Labor, pp. 110-111.

14 Ibídem.

15 Cfr. Ibídem, p 17.
} 
Hoy nos encontramos ante nuevas realidades que son el producto último de una profunda transformación social, cultural, educativa, económica, política, informativa y legislativa. Además, en opinión de la profesora de Periodismo Nieves García González: "Estas nuevas realidades presiden sociedades democráticas, entre las que se encuentra la nuestra. En esta nueva circunscripción resulta imperante la opinión pública, ya que va a ser el catalizador que traduce sus efectos en esta nueva sociedad a la que los medios de comunicación informan y de la que, a su vez, se nutren"16 (García

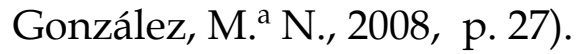

De esta forma, todos los lenguajes son convenciones aceptadas. Se tiende a interpretar algunos símbolos de la misma manera por cualquier persona integrante de un grupo definido. Los artistas y filósofos pueden influir en los demás introduciendo nuevos símbolos y reglas y rechazando los antiguos ${ }^{17}$ (Arijón, D., 2003). Además, los lenguajes de los medios audiovisuales deben ser utilizados con el máximo rigor por los profesionales de la información. En la comunicación audiovisual, el lenguaje indirecto es el único capaz de conmover, de garantizar el movimiento del sentimiento, de la emoción. Un ejemplo son los campos vacíos. Son esas pausas en la imagen, esos momentos de suspense en la constante aparición de todo lo que da acceso al pensamiento. Este lenguaje indirecto puede garantizar la elaboración de la sensibilidad frente a la pasividad y la indiferencia ${ }^{18}$.

\section{METODOLOGÍA}

Los nuevos soportes de comunicación en formato escrito, utilizados especialmente entre los jóvenes, como -bitácoras o blogs, los chats de Internet o los mensajes SMS de los teléfonos móviles-, así como la interacción a través de la Red, propician el desarrollo de una escritura actual propia del lenguaje juvenil, por ejemplo: las abreviaturas, la pérdida de vocales, la falta de puntuación y de acentuación, etc.

Se ha investigado uno de los más novedosos soportes en la Red, los Twittersodios, que fueron aplicados en la serie El Barco. Su página Web, con la incorporación de este fenómeno, es un claro ejemplo del mal uso de la Lengua Española, en el que, entre otras desviaciones lingüísticas, hay que destacar la utilización oralizada del discurso en la redacción de los mensajes.

\section{ANÁLISIS Y DISCUSIÓN}

En Estados Unidos hace algún tiempo que las series de televisión experimentan las posibilidades de Internet como plataforma para crear expectación. En España, las series aún no han dado el salto en su totalidad a la Red. La producción de ficción

\footnotetext{
16 García González, M. ${ }^{a}$ N. (2008). Periodismo, Publicidad, Cine, Comunicación Audiovisual y Relaciones Públicas. Iconos para un lenguaje democrático. Un enfoque interdisciplinar para el aprendizaje de los Estudios Superiores. Madrid: Fragua, p. 27.

17 Arijón, D. (2003). Gramática del lenguaje audiovisual. Andoain: Escuela de Cine y Vídeo.

${ }_{18}$ Musicco, D. (2007). El campo vacío. El lenguaje indirecto en la Comunicación Audiovisual. Madrid: Cátedra.
} 
nacional está revolucionando la denominada narrativa transmedia, técnica que permite contar historias a través de múltiples plataformas y soportes en las que los usuarios colaboran en la construcción del relato. En España, el uso de las redes sociales se estrenó con La pecera de Eva, serie de Telecinco que en poco tiempo pasó a emitirse en La siete. Esta serie creó una página en Facebook con más de 130.000 seguidores y un Twitter de Eva, la psicóloga protagonista.

Antena 3 Televisión se ha desmarcado como una cadena innovadora con la emisión de la serie El Barco, ya que cinco días antes de su estreno introdujo una novedad que ha revolucionado a sus múltiples seguidores. Se trata de los Twittersodios, episodios presentados en Twitter y en los que se pueden seguir los diálogos en forma de tuiteos de los personajes de la serie. Es decir, no se trata de vídeos, sino que utilizan Twitter, sólo textos y diálogos, aunque añaden enlaces a imágenes o vídeos que contengan pistas, material adicional o desbloqueable. Tras el Twittersodio, se publica en la Web un resumen del capítulo.

Además de seguir los comentarios de los personajes y sus diálogos, los seguidores de la serie pueden interactuar con ellos usando el hashtag\#elbarco. De esta forma, se crea una comunidad fiel en la Red al utilizar una de las herramientas de comunicación que más presencia tiene en los últimos tiempos, Twitter.

Consecuentemente, hay posibilidades de que otras series nacionales ejerciten su creatividad más allá de la televisión.

\section{EJEMPLOS:}

\section{BEstrellaPolar Aquí: http://t.co/sntkNJ97 \#FastPlay\#Elbarco RT}

@minijorna: @BEstrellaPolar Donde se puede ver la clasi en directo? hace 20 horas.

- $B e$ (Se escribe VE, por ser verbo).

- La "a" de "Aquí" sería minúscula.

- Falta la tilde en Dónde y, además, el signo interrogativo de apertura.

- Confusión de la vocal - $i$ en lugar de la -e de clasi por clase.

- Omisión de la mayúscula después del signo interrogativo de cierre en "hace". 
BEstrellaPolar Sí ;) RT @AnuskaSantiago: @BEstrellaPolar Alex gana una batalla con 14 puntos? XD Eso es que Diego atacó sin Balas? jajajajaja \#FastPlay

- $B e$ (Se escribe VE, por ser verbo).

- Uso de emoticonos ;) (sonrisa).

- Falta el signo interrogativo de apertura y la tilde en "Alex".

- Uso de abreviaturas: XD en lugar de "por Dios".

- Uso de onomatopeyas: jajajajaja.

- Utilización de anglicismos: Fast Play: juego rápido.

\section{Maribel_Marron Quiero que vuelva \#elbarco: (RT si tu tambien quieres! :}

- Falta la tilde en "Marron" y, a continuación, un punto y seguido.

- Igualmente, faltan las tildes en "si", "tu" y "tambien".

- Omisión de la coma después de "si".

\section{notremixed maldito gamboa $\mathrm{D}:<<<<$ \#elbarco}

- Omisión de los signos exclamativos. ¡Maldito Gamboa!

- Abreviatura de Dios (D).

- Utilización de signos matemáticos: $<<<<<$.

815marina "@belii8mc:nunca me había dado cuenta qe el chico que sale en \#aida en este capítulo era Palomares de \#elBarco"ajajame acba de psar lo msmo!

- Hay que indicar la mayúscula en el nombre propio "marina".

- Queísmo: nunca me había dado cuenta "qe" el chico... Lo correcto es Nunca me había dado cuenta $D E$ que el chico...

- Hay que indicar la mayúscula en el nombre propio "Aida". 
- Omisión de la vocal " $u$ " en "qe".

- Uso de onomatopeyas: ajajame.

- Omisión de la vocal "a" en "acba" y en "psar".

- Omisión de la vocal " $i$ " en "msmo".

Mayte_MC_BS Alguien sabe sí se ha confirmado ya la fecha de la emisión de el especial navidad de\#elbarco ??

- Falta el signo interrogativo de apertura.

- Sobra la tilde de "sí", ya que se trata de un condicional.

- Hay que contraer "de" y "el". Sería emisión DEL especial.

- La palabra "navidad" es con mayúscula, ya que es nombre propio.

- Sobra un signo interrogativo de cierre.

aguedapuy Que el cura de \#elbarco, ahora actua en\#Aídaa! y fidel se a enamorado de el.

- Omisión de las mayúsculas iniciales en "águeda" y "puy"; falta la separación.

- Faltan el punto y seguido y el signo exclamativo de apertura antes de "Que".

- Omisión de la tilde en la " $u$ " de "actua", ya que se trata de un hiato.

- Sobra una vocal "a" en "Aidaa".

- Falta la "F" mayúscula en "fidel".

- Falta la " $h$ " en " $a$ ", ya que es del verbo haber y va seguido del participio "enamorado".

- Falta la tilde en "el" porque es pronombre.

anagonzalezbt aun me quedan por ver 3 capitulos de \#ElBarco y eso que hoy he visto dos.

- Omisión de las mayúsculas iniciales en "ana" y "gonzález"; falta la separación. 
- Falta la tilde en la " $u$ " de "aun" porque es bisílaba y se puede sustituir por "todavía".

- Falta la tilde en la "i" de "capitulo" porque es una palabra esdrújula.

\section{Loreaisidro Perdi el control, me rebente los nudillos pegandole, y de paso perdia lo mas bonito que tenia en mi vida \# estoyenamoradadeUlises \#Elbarco}

- Falta el punto y seguido antes de "Perdi".

- Falta la tilde en la " $i$ " de "Perdi" porque es una palabra aguda acabada en vocal.

- Sobra el espacio antes de la coma de "control".

- Error ortográfico en la expresión "me rebente"; sería me reventé.

- Falta la tilde en la " $i$ " de "perdia" porque es un hiato.

- Faltan las tildes en "pegandole", "mas" y "tenia".

\section{blancasuarezweb Blanca Suárez, candidata a la nominación del TP de ORO a Mejor actriz por\#elbarco. No dudéis en votarla como favorita:http://t.co/7UCB44g0}

- Omisión de las mayúsculas iniciales en "blanca" y "suárez"; falta la separación.

- Falta el artículo "la" antes del sustantivo "actriz".

\section{CONCLUSIONES}

Parece evidente que la lengua, en general, y la lengua de la comunicación electrónica, en particular, están en un proceso de cambio generacional. Prueba de ello es el binomio comunicación y mensaje, apoyado por las Nuevas Tecnologías, lo que ha provocado el nacimiento del discurso digital multimedia y que contiene elementos visuales, acústicos, lingüísticos y no lingüísticos. De esta forma, las Tecnologías de la Información y de la Comunicación (TIC) provocan cambios culturales en nuestra lengua que, en mayor o menor medida, nos afectan en todos los ámbitos. 
En el complejo armazón que constituye hoy el producto multimedia, la aceptación de las metáforas culturales dependerá de cómo se han tenido en cuenta las expectativas del usuario en la adaptación lingüística. La Lengua Española está formada por vocablos procedentes del griego, el latín, el árabe, el francés, el italiano, etc. En ella, el leísmo y el laísmo, por citar únicamente dos ejemplos, son fenómenos lingüísticos presentes en cualquier registro, pero, actualmente, el punto de atención se centra en la ortografía tanto de los SMS, como de todos los mensajes a través de la Red, acusados de fomentar el ocio en detrimento de la lectura.

Los principales consumidores de las Nuevas Tecnologías, los jóvenes, utilizan un estilo de lenguaje que algunos lingüistas consideran como la jerga propia (o juvenil), que surge entre iguales, en situaciones de comunicación no formales y, sobre todo, orales; y la lengua estándar, que los muchachos utilizan para comunicarse. Su jerga destaca por ser creativa, original e ingeniosa.

Sin embargo, el lenguaje juvenil es pobre e incorrecto y se afirma que las causas no solo hay que buscarlas en las Nuevas Tecnologías, sino, también, en el sistema educativo, lo que lleva a la triste realidad de que, en algunos licenciados, también se aprecie una notable pobreza léxica debido en gran parte a una falta de registros que deberían haber adquirido a lo largo de su formación.

Una muestra de las desviaciones lingüísticas cometidas por los denominados nativos digitales ha quedado patente en la investigación realizada a través de la página Web de la exitosa serie El Barco. Aunque asistimos a la irrupción de nuevas formas de comunicación en los medios: la página Web, el correo electrónico, el chat, los SMS, etc., éstas tendrían que adaptarse a la normativa lingüística actual.

Por tanto, las líneas precedentes pudieran inducirnos a pensar que ha surgido una nueva forma de escritura, ya que el discurso oralizado se traslada a la plataforma de Internet, donde se demuestra la necesidad del ser humano por la comunicación a través de las tecnologías cibernéticas. En ellas, nos comunicamos y escribimos cada vez con más actividad; ahora bien, no conviene dar por supuesto que "todo se entiende". Si tomamos como referencia a quien cuidó especialmente el buen uso del español, Fray Luis de León nos decía: "Tan importante es lo que se escribe como la manera en la que se escribe".

\section{BIBLIOGRAFÍA}

Arijón, D. (2003). Gramática del lenguaje audiovisual. Andoain: Escuela de Cine y Vídeo.

Berlo, K. D. (1969). El proceso de la comunicación: Introducción a la teoría y la práctica. Buenos Aires: El Ateneo.

Blake, Reed, H. y Haroldsen, E. O. (1989). Una taxonomía de conceptos de la comunicación. México: Nuevomar. 
Cloutier, J. (1975). L'ere d'emerec. Montreal: Les Presses de l'Université de Montréal.

Eco, U. (1999). Apocalipticos e Integrados. Barcelona: Lumen.

- (1976). Signo. Barcelona: Labor.

Galán, C. (2009). "El lenguaje del teléfono móvil". En: Sarmiento, R. y Vilches, F. (coord). La calidad del español en la Red. Nuevos usos de la lengua en los medios digitales. Barcelona: Ariel; Madrid: Fundación Telefónica.

García, M. ${ }^{a}$ N. (2008). Periodismo, Publicidad, Cine, Comunicación Audiovisual y Relaciones Públicas. Iconos para un lenguaje democrático. Un enfoque interdisciplinar para el aprendizaje de los Estudios Superiores. Madrid: Fragua.

González, J. y Moure, A. (2000). El origen del Hombre. Historia de la humanidad. Madrid: Alianza.

Kaplún, M. (1998). Una pedagogía de la comunicación. Madrid: de la Torre.

Lázaro Carreter, F. (1981). Curso de Lengua Española. Madrid: Anaya.

Lloret, N. y Canet, F. (2006). "Nuevos escenarios, nuevas formas de expresión narrativa: la Web 2.0 y el lenguaje audiovisual". En: Hipertext.net, n. ${ }^{\circ} 6$.

Musicco, D. (2007). El campo vacío. El lenguaje indirecto en la Comunicación Audiovisual. Madrid: Cátedra.

Ortega y Gasset, J. L. (1987). La rebelión de las masas. Madrid: Alianza.

Sénecal, Michel (1995). ¿La interconectividad conduce a la democracia? En: El Correo de la Unesco, vol. 48. París: Unesco, pp. 16-18.

http:/ / enebro.pntic.mec.es/ phum0000/cam/temados.htm\#cinco

(Consultado el 2/12/2011).

http:/ / www.adilq.com.ar/Resumen\%20Galera\%20Julieta-

Calandrelli\%20Roc\%EDo.pdf (Consultado el 20/12/2011).

\section{Carlos Oliva Marañón}

Doctor en Ciencias de la Comunicación. Profesor de la Facultad de Ciencias de la Comunicación de la Universidad Rey Juan Carlos en las áreas de Periodismo, Comunicación Audiovisual y Magisterio. Autor, entre otras publicaciones, de las siguientes: Calidad, visibilidad e interactividad: paradigmas de las Universidades Virtuales en España; Sociólogos: competencias, formación universitaria y sinergias cognitivas en el Espacio Europeo de Educación Superior (EEES); Fundamentos lingüísticos del lenguaje periodístico y jurídico-administrativo; La creación léxica mediante siglas: un recurso de condensación expresiva en la prensa digital; Redes sociales y jóvenes: una intimidad cuestionada en Internet. 
Lengua Española - Entorno digital - Competencia escrita - Series de Televisión - Redes Sociales

Ha trabajado en diferentes Organismos Oficiales como la Consejería de Educación de la Comunidad de Madrid, las Cortes Generales y el Instituto Cervantes. 